\title{
Ein paar Eier pro Woche machen keinen Diabetes
}

\author{
Eier werden als Nahrungsmittel kritisch beäugt. Zumindest hinsichtlich der Entwicklung eines \\ Diabetes gibt eine Metastudie nun aber Entwarnung: Drei Eier pro Woche sind kein Risikofaktor!
}

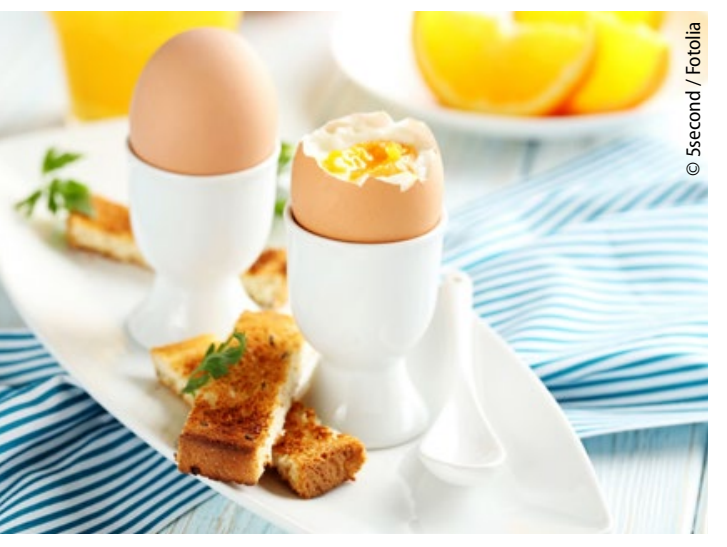

Ein leckeres Frühstücksei kann man sich ohne Angst vor Diabetes gönnen.

Für eine Metaanalyse wurden alle prospektiven Kohortenstudien eingeschlossen, die sich mit der Beziehung zwischen dem Verzehr von Eiern und dem Risiko für die Entwicklung eines Diabetes mellitus beschäftigten. In den Datenbanken PubMed, Ovid, Cochrane und Google Scholar up wurden alle bis Oktober 2015 publizierten Arbeiten identifiziert.

Der primäre Endpunkt der Studien war die Diagnose Diabetes mellitus. Meist wurden die Kriterien der US-amerikanischen Diabetesgesellschaft genutzt: Nüchternblutzuckerwert $\geq 126$ $\mathrm{mg} / \mathrm{dl}$ bzw. $\geq 7,0 \mathrm{mmol} / \mathrm{l}, \mathrm{HbA}_{\mathrm{lc}}$-Wert $\geq$ $6,5 \%$ bzw. $\geq 48 \mathrm{mmol} / \mathrm{mol}$ oder Zwei-
Stunden-Glukose-Toleranzwert $\geq 200$ mg/dl bzw. $\geq 11,1 \mathrm{mmol} / \mathrm{l}$. Die Daten wurden von zwei unabhängigen Autoren analysiert.

Von 1.990 erfassten Studien erfüllten 12 die methodischen Anforderungen. Sieben davon wurden in den USA erhoben. Der Beobachtungszeitraum lag zwischen 5 und 20 Jahren, die Teilnehmerzahl zwischen 2.332 und 65.364 .

In den 12 Studien wurden insgesamt 219.979 Personen analysiert. 8.911 entwickelten einen Diabetes mellitus. Das gepoolte multivariante relative Risiko für Diabetes mellitus lag mit dem höchsten Konsum von Eiern verglichen mit dem niedrigsten Konsum bei 1,09 (95\%-Konfidenzintervall [KI]: 0,991,20) bei Gebrauch des Fixed-EffectsModells und bei 1,06 (95\%-KI: 0,86$1,30)$ bei Berücksichtigung des RandomEffects-Modells. Eine Evidenz für Heterogenität wurde ausgeschlossen (I2 = $73,6 \%, \mathrm{p}<0,001)$.

Bei der Betrachtung nach geografischer Herkunft zeigten sich Unterschiede. In Studien aus den USA zeigte sich bei hohem Eierkonsum im Vergleich zum niedrigsten Konsum ein um 39\% höheres Risiko für die Entwicklung eines Diabetes (95\%-KI: 21\%-60\%). In den Studien aus den anderen Ländern konnte kein signifikanter Unterschied ermittelt werden $(\mathrm{p}<0,001)$.
Mengenmäßig ergab sich kein Zusammenhang zwischen einem regelmäßigen Konsum von $<4$ Eiern pro Woche und der Entwicklung eines Typ2-Diabetes. Nur in vier der US-Studien stieg das Risiko ab drei Eiern pro Woche, was an der beliebten Kombination mit Speck oder Fleisch liegen könnte.

- Djoussé L, Khawaja OA, Gaziano JM. Egg consumption and risk of type 2 diabetes: a meta-analysis of prospective studies. Am J Clin Nutr. 2016;103:474-80

\section{KOMMENTAR}

Es ist das Verdienst dieser Studie, den schlechten Ruf von Eiern als Nahrungsmittel zu relativieren. Zumindest in Europa und Japan und sogar in einigen der amerikanischen Studien fand sich kein Zusammenhang zwischen einem moderaten Konsum von Eiern und der Entwicklung eines Typ2-Diabetes. Dies ist wichtig vor dem Hintergrund, dass Eier eine sehr gute Protein- und Vitaminquelle darstellen und überall auf der Welt zu relativ geringem Preis verfügbar sind. Zusammenfassend bestätigen die Daten, dass genetische Disposition, mangelnde körperliche Aktivität sowie Übergewicht bzw. Adipositas weiterhin die entscheidenden Determinanten für die Entwicklung eines Typ-2-Diabetes sind. Der Verzehr und die Menge einzelner Nahrungsprodukte, wie hier für Eier gezeigt werden konnte, haben dagegen keinen nennenswerten Einfluss.

Dr. med. C. Jaursch-Hancke

\section{Hier steht eine Anzeige.}

